\title{
Клинический случай «синдрома после поражения сердца» после радиочастотной катетерной абляции фибрилляции предсердий и трепетания предсердий
}

\author{
Суслина Ю. И. ${ }^{1}$, Мешкова М. С. ${ }^{1}$, Доронин А. В. ${ }^{2}$ \\ ${ }^{1}$ ГУ «Научно-практический медицинский центр детской кардиологии и кардиохирургии МЗ Украины» \\ (Киев) \\ ${ }^{2}$ Национальная медицинская академия последипломного образования имени П. Л. Шупика (Киев)
}

\begin{abstract}
«Синдром после поражения сердца» (СППС) - общий термин, объединяющий воспалительные перикардиальные синдромы: перикардит после инфаркта миокарда, постперикардиотомический синдром, ятрогенный и не ятрогенный посттравматический перикардит. Частота развития этой патологии в кардиохирургической практике достаточно большая - от 10 до 40\%. Цель статьи - описать клинический случай и акцентировать внимание на СППС как возможном осложнении катетерной абляции. Материалы и методы. В статье приводится случай «синдрома после поражения сердца», развившегося после радиочастотной катетерной абляции фибрилляции и трепетания предсердий. Результаты и обсуждение. Для лечения патологии с успехом применялись НПВП и колхицин. Выводы. Несмотря на большую частоту развития СППС в кардиохирургической практике, сообщения о возникновении этой патологии после катетерных абляций встречаются редко. Основное место в диагностике СППС принадлежит трансторакальной ЭхоКГ и мониторированию воспалительных маркеров крови, в частности СРП. Для лечения СППС применяют НПВП и колхицин.
\end{abstract}

Ключевые слова: «синдром после поражения сердца», радиочастотная катетерная абляция, фибрилляция предсердий, трепетание предсердий.

«Синдром после поражения сердца» (СППС) (postcardiac injury syndrome, PCIS) - это общий термин, объединяющий воспалительные перикардиальные синдромы и включающий перикардит после инфаркта миокарда, известный как синдром Дресслера, постперикардиотомический синдром и посттравматический перикардит (в том числе ятрогенный) [1]. Развитие этой патологии встречается не только после хирургических манипуляций, сопровождающихся рассечением перикарда, но и после перкутанных коронарных вмешательств, имплантации искусственного водителя ритма сердца, радиочастотной катетерной абляции (РЧКА) субстрата аритмии.

Частота развития СППС в кардиохирургической практике составляет от 10 до 40\% [2]. Группу риска составляют пациенты молодого и среднего возраста (47士20 лет) [3].

Предполагают, что патогенез СППС связан с повреждением миокарда вследствие некроза или травмы, в том числе ятрогенной, и имеет аутоиммунный механизм развития. Ведущую роль играет образование аутоантител к клеткам сердца (антисарколемных и антифибриллярных антител) в результате антигенной стимуляции, связанной с повреждением тканей сердца [4].
Время манифестации СППС составляет от одной до шести недель после хирургического вмешательства или острого инфаркта миокарда. Однако Koller M. L., Tang R. и Sasaki A. описывают случаи развития СППС через один-три дня после РЧКА трепетания и фибрилляции предсердий, а также имплантации искусственного водителя ритма [6-8].

Диагноз СППС может быть поставлен на основании клинических критериев: лихорадка без других причин; боль в грудной клетке, связанная с плевритом или перикардитом; шум трения перикарда или плевры; наличие перикардиального и/или плеврального выпота и повышение С-реактивного протеина (СРП). Для подтверждения диагноза СППС необходимо наличие хотя бы двух из перечисленных критериев и их связь с повреждением сердца [1].

Для лечения СППС используется та же схема, что и для лечения перикардита. Терапия основана на применении высоких доз нестероидных противовоспалительных препаратов (НПВП) и аспирина (рекомендация класса I, уровень доказательств А, согласно ESC 2015) и назначении колхицина как добавления к НПВП/аспирину (рекомендация класса I, уровень доказательств А, согласно ESC 2015) [1]. 
Прогноз при постперикардиотомическом синдроме обычно хороший [8]. О других формах СППС в литературе мало данных.

Цель статьи - описать случай развития СППС после РЧКА фибрилляции и трепетания предсердий и акцентировать внимание на СППС как возможном осложнении абляции.

Клинический случай. Женщина 63 лет с частыми симптомными пароксизмами фибрилляции и трепетания предсердий, не поддающимися контролю ритма на фоне приема пропафенона, поступила в «Научнопрактический медицинский центр детской кардиологии и кардиохирургии МЗ Украины» для проведения хирургического лечения нарушений ритма.

Материалы и методы. Рутинные обследования при поступлении. ЭКГ: синусовый регулярный ритм. ЧСС 68 уд./мин. Депрессий и элеваций сегмента ST на момент поступления не зафиксировано. ЭхоКГ: полости сердца (в том числе левое предсердие: диаметр 39 мм, S 19,8 см²) не дилатированы, сократительная функция миокарда левого желудочка (ЛЖ) не снижена (ФВ 4С - 58\%), небольшая аортальная недостаточность и небольшая митральная недостаточность дегенеративного генеза; диастолическая дисфункция ЛЖ I тип. В полости перикарда и плевральных полостях выпота обнаружено не было.

В клиническом анализе крови лейкоцитоза, палочкоядерного сдвига и увеличения СОЭ не зафиксировано.

Материалы и методы. В плановом порядке пациентке была выполнена радиочастотная катетерная изоляция правых и левых легочных вен с транссептальным доступом и создана блокада проведения по кавотрикуспидальному перешейку. Для абляции использовался неорошаемый электрод (7 Fr, Therapy, St. Jude Medical Inc., USA), который доставлял к субстрату радиочастотную энергию с параметрами $55^{\circ} \mathrm{C}, 35 \mathrm{~W}$. Продолжительность каждой аппликации составляла 40 секунд. За время процедуры выполнено 106 аппликаций. Операция проходила и была завершена типично. После выполнения транссептальной пункции и окончания процедуры абляции производился эхокардиографический контроль наличия жидкости в перикарде. Жидкости в перикарде зафиксировано не было.

На вторые сутки после операции у пациентки появились жалобы на боль в грудной клетке слева, усиливающуюся при глубоком вдохе, субфебрильная температура. При ЭхоКГ сепарации листков перикарда обнаружено не было. Клинический анализ крови выявил лейкоцитоз, увеличение количества палочкоядерных нейтрофилов и увеличение СОЭ.

Была начата терапия НПВП и антибиотиком цефалоспоринового ряда. Через несколько дней температура тела нормализовалась, боли исчезли. При проведении ЭхоКГ был обнаружен выпот в полость перикарда (сепарация листков перикарда по задней стенке ЛЖ в парастернальной позиции по длинной оси составила 9 мм). Серия последующих эхокардиограмм за период наблюдения показала наличие выпота в полость перикарда (максимальная зафиксированная сепарация листков перикарда по задней стенке ЛЖ в парастернальной позиции по длинной оси составила 14 мм). Ультразвуковое исследование плевральных полостей показало наличие выпота в обеих полостях. На контрольных рентгенограммах вовлечения в патологический процесс паренхимы легких обнаружено не было. Отмечался рост СРП (максимальное значение 107.37 мг/л, норма 5-10 мг/л), уровня лейкоцитов (максимальное значение 14.8х109/л) и СОЭ (максимальное значение 90 мм/час). Плевроцентез и перикардиоцентез не проводился.

На пятые сутки после операции была начата терапия колхицином в дозе 0,5 мг внутрь два раза в сутки.

Результаты и обсуждение. В течение двух недель от начала приема колхицина количество выпота в полости перикарда уменьшилось (сепарация листков перикарда по задней стенке ЛЖ в парастернальной позиции по длинной оси составила 4-5 мм).

В левой плевральной полости оставалось незначительное количество выпота, в правой плевральной полости выпот не визуализировался. Уровень СРП снизился до 28.18 мг/л, лейкоцитов - до $10.8 \times 10^{9} / л$, СОЭ - до 50 мм/ час. Пациентка была выписана из стационара с рекомендациями продолжать лечение НПВП и колхицином. При проведении контрольной ЭхоКГ через месяц было обнаружено увеличение количества перикардиального и плеврального выпота. СРП на момент осмотра составлял 42 мг/л. Пациентке рекомендовано продолжение приема колхицина в дозе 1 мг внутрь два раза в сутки, контроль ЭхоКГ и СРП. Длительность приема колхицина до исчезновения признаков плеврального и перикардиального выпота и нормализации уровня СРП составила 4 месяца. Общий период наблюдения пациентки составил 8 месяцев.

\section{Выводы}

- Несмотря на достаточно большую частоту развития СППС в кардиохирургической практике, сообщения о возникновении этой патологии после катетерных абляций встречаются редко.

- Основная роль в диагностике СППС принадлежит трансторакальной ЭхоКГ и мониторированию воспалительных маркеров крови, в частности СРП.

- Для лечения СППС применяют НПВП и колхицин. Длительность терапии зависит от сроков нормализации СРП.

\section{Литература}

1. Guidelines for the diagnosis and management of pericardial diseases: The Task Force for the Diagnosis and Management of Pericardial Diseases of the European Society of Cardiology (ESC) / Yehuda Adler, Philippe Charron, Massimo Imazio et al. // European Heart Journal. - 2015. - Vol. 36 (42). - P. 2921-2964. DOI: 
https://doi.org/10.1093/eurheartj/ehv318 Published: 07 November 2015

2. Post-cardiac injury syndrome / M. Jaworska-Wilczyńska, M. Kúsmierczyk, E. Abramczuk, T. Hryniewiecki // Kardiochirurgia i Torakochirurgia Polska. - 2013. - Vol. 10 (1). - P. 20-26.

3. Behavior of inflammatory markers of myocardial injury in cardiac surgery: laboratory correlation with the clinical picture of postpericardiotomy syndrome / Kuhler I., Saraiva P. J., Wender O. B., Zago A. J. // Arq Bras Cardiol. - 2003. - Vol. 81. - P. 279-290.

4. Wessman D. E. The postcardiac injury syndrome: case report and review of the literature / D. E. Wessman, C. M. Stafford // South Med. J. - 2006.

5. Драненко Н. Ю. Постперикардиотомный синдром: механизмы патогенеза и критерии диагноза // Таврический медико-биологический вестник. - 2013. - Том 16, №4 (64). - C. 42-49.
6. Postcardiac injury syndrome following radiofrequency ablation of atrial flutter / Koller M. L., Maier S. K., Bauer W. R., Schanzenbacher P. // Z Kardiol. - 2004. Vol. 93. - P. 560-5.

7. Postcardiac injury syndrome complicating circumferential pulmonary vein radiofrequency ablation for atrial fibrillation / Tang R. B., Liu X. H., Dong J. Z. et al. // Chin Med J (Engl). - 2007. - Vol. 120. - P. 1940-2.

8. Incidence and clinical characteristics of postcardiac injury syndrome complicating cardiac perforation caused by radiofrequency catheter ablation for cardiac arrhythmias / Yang Liu, Chao Wang, Ruifu Zhao // International Journal of Cardiology. - 2013. - Vol. 168. - P. 3224-9.

9. Meta-analysis of randomized trials focusing on prevention of the postpericardiotomy syndrome / Imazio M., Brucato A., Markel G. et al. // Am J Cardiol. - 2011. Vol. 108. - P. 575-579.

\title{
Case report. Postcardiac injury syndrome following radiofrequency ablation for atrial fibrillation and atrial flutter
}

\author{
Suslina Y. ${ }^{1}$, Meshkova M. ${ }^{1}$, Doronin A. ${ }^{2}$ \\ ${ }^{1}$ Ukrainian Children's Cardiac Center (Kyiv) \\ 2 Shupyk National Medical Academy of Postgraduate Education (Kyiv)
}

Post-cardiac injury syndrome (PCIS) is a common term that covers such inflammatory pericardial syndromes: postmyocardial infarction pericarditis, post-pericardiotomy syndrome, iatrogenic and non-iatrogenic post-traumatic pericarditis. Rates of this pathology are rather high in a cardiosurgical practice (from 10\% to 40\%). This article aims at describing a clinical case and focusing on the PCIS as a possible ablation complication. Materials and methods. This article discusses a clinical case of the post-cardiac injury syndrome following the radiofrequency catheter ablation of atrial fibrillation and atrial flutter. Results and discussion. For the treatment of pathology successfully used NSAIDs and colchicine. Conclusions: despite high PCIS rates in a cardiosurgical practice, this abnormality as it follows catheter ablations is rarely reported. Transthoracic echo and monitoring of inflammatory blood markers, in particular CRP, are central to PCIS diagnosis. NSAIDs and colchicine are used to treat the PCIS.

Key words: post-cardiac injury syndrome, radiofrequency catheter ablation, atrial fibrillation, atrial flutter.

\section{Клінічний випадок «синдрому після ураження серця» після радіочастотної катетерної абляції фібриляції передсердь і тріпотіння передсердь}

\author{
Сусліна Ю. І. ${ }^{1}$, Мешкова М. С. ${ }^{1}$, Доронін О. В. ${ }^{2}$ \\ ${ }^{1}$ ДУ «Науково-практичний медичний центр дитячої кардіології та кардіохірургії МОЗ України» (Київ) \\ ${ }^{2}$ Національна медична академія післядипломної освіти імені П. Л. Шупика (Київ)
}

«Синдром після ураження серця» (СПУС) - спільний термін, що об’єднує запальні перикардіальні синдроми: перикардит після інфаркту міокарда, постперикардіотомічний синдром, ятрогенний та не ятрогенний післятравматичний перикардит. Частота розвитку цієї патології в кардіохірургічній практиці достатньо значна - від 10 до $40 \%$. Мета статті - описати клінічний випадок і акцентувати увагу на СПУС як можливому ускладненні абляції. Матеріали та методи. У статті наведено випадок «синдрому після ураження серця», що виник після радіочастотної катетерної абляції фібриляції та тріпотіння передсердь. Результати та обговорення. Для лікування патології з успіхом було застосовано НПЗП та колхіцин. Висновки. Незважаючи на велику частоту розвитку СПУС у кардіохірургічній практиці, повідомлень про виникнення цієї патології після катетерних абляцій небагато. Основне місце в діагностиці СПУС належить трансторакальній ЕхоКГ та моніторуванню маркерів запалення, зокрема СРП. Для лікування СПУС використовують НПЗП та колхіцин.

Ключові слова: «синдром після ураження серия», радіочастотна катетерна абляція, фібриляція передсердь, тріпотіння передсердь. 